\title{
Denturism (Clinical Dental Technology) - a brief review
}

SADJ November 2019, Vol. 74 No. 10 p575 - p577

CP Owen

\section{SUMMARY}

The term 'denturism' is most commonly used worldwide for either dental technicians who are trained clinically, usually in removable prosthodontics, or for people who are trained specifically in that field to carry out both the laboratory and clinical procedures.

In South Africa the term used is 'clinical dental technologist' and was introduced as an amendment to the Dental Technicians Act in 1997. However, this oral health professional has never been defined and no regulations have been promulgated.

The South African Dental Technician's Council will be investigating the appropriate regulatory framework to provide for the enactment of clinical dental technology, and so the purpose of this paper is to give some background to denturism in general and to make suggestions as to the guidelines to be followed were it to be established in South Africa.

\section{Keywords}

Denturism, denturist, dental prosthetist, clinical dental technologist.

\section{INTRODUCTION}

"Denturism" is the most commonly used term worldwide for what is essentially a clinical dental technologist. The latter term has entered the legislation in South Africa but this has never been enacted.

In this brief review, the term "denturism" will be used throughout. The South African Dental Technician's Council will be investigating the appropriate regulatory framework to provide for the enactment of clinical dental technology, and so it was felt that some background to this profession may be useful.

\section{A brief history}

Denturism had a somewhat patchy start in different parts of the world, but seems to have developed from wartime experiences, emerging as dental technology

\section{Author affiliation:}

C Peter Owen: BChD, MSc (Dent) MChD, FCD (SA),

Professor Emeritus, Faculty of Health Sciences, University of the

Witwatersrand, Johannesburg.

ORCID Number: 0000-0001-6820-0875

Corresponding author: C Peter Owen

Faculty of Health Sciences, University of the Witwatersrand,7 York Road

Parktown, Johannesburg, South Africa.

Email: peter.owen@wits.ac.za from the 1914-18 war when dental assistants were trained to help military dentists not only at the chairside but also in the laboratory. ${ }^{1}$ Subsequently some remained as dental technicians in independent laboratories.

However, during the depression years, it was discovered that some dental technicians were providing a clandestine service and this seems to have been the origin of the subsequent and ongoing distrust between dentists and technicians.

In Canada these dental technicians started to organise amongst themselves and by the mid-1970s were known as Denturists. Only two Canadian provinces still prohibit denturism. The same appeared to have happened in New Zealand, a country which was the first to introduce a range of dental auxiliaries, including denturists.

Several countries now allow for denturists, though each with different legislation governing their scopes of practise. These include all but two of the provinces of Canada, New Zealand, Australia, five states of the USA, Belgium, Denmark, Holland, Malta, Finland, Poland, Iraq, Israel and Switzerland.

In the UK, there has been quite vehement opposition to denturism and the British Dental Association (not unlike the South African Dental Association) is a strong political force that is antagonistic toward the profession (although in the scope of maxillo-facial prosthodontics, dental technicians are allowed to be in contact with patients, but only for extra-oral prostheses). ${ }^{2}$

There has been very little published in peer-review journals concerning denturism, but much emotive and anecdotal information can be found on the internet.

This brief review will only look at peer-reviewed articles and try to draw some conclusions that may be pertinent to South Africa.

\section{Scope of practice}

This seems to vary from treating only edentulous patients to the provision of all removable prostheses. Most countries seem to have started with the treatment of edentulous patients and some have then expanded this to include removable partial dentures (RPDs).

In four of the five states in the US that allow denturism, denturists must practice under the supervision of a dentist. Only in Oregon can they enter independent 
practice. In Finland, denturists are only licensed to provide a complete denture service (including relining and repairing) for "an already edentulous jaw free of pathological or congenital anomalies". ${ }^{3}$ However, a large number of RPDs are carried out illegally by denturists as well as dental technicians, often when a patient requires a complete denture as well as an RPD.

The study concluded by stating that "The results of this study give reason to believe that denturists' right to provide complete dentures directly to the public leads to illegal provision of partial dentures as well" which must be of some concern to any country wishing to introduce denturism.

In New Zealand, denturists provide complete dentures as well as RPDs, but a dentist must provide on oral health certificate before a denturist can treat patients for RPDs. ${ }^{4}$ Four out of five denturists reported that they provide both metal and acrylic-based RPDs.

In Australia denturists are registered to manufacture complete dentures, partial dentures, and mouthguards. ${ }^{5}$

\section{Education}

Very little has been published on the training of denturists. In Canada, it appears that there is little or no training in pathology or diagnoses ${ }^{1}$ and in some provinces denturists must, prior to undertaking treatment, refer patients to dentists for confirmation that the mouth is sufficiently healthy to support a denture.

In an Australian survey of denturists, 99\% of respondents reported that they checked new patients and $86 \%$ checked recall patients for oral mucosal pathology; $86 \%$ reported that they had detected a suspicious lesion and $77 \%$ had referred for a suspicious lesion. ${ }^{5}$

An advanced diploma of dental prosthetics in that country is completed part-time over two years, comprising 20 units of study. ${ }^{5}$ However, because only a single unit is devoted to oral mucosal pathology, there have been calls to increase the length and level of training to a 3-year bachelor's degree.

In a 1994 review of denturism in Canada, ${ }^{1}$ MacEntee pointed out that the dentists, dental technicians, and denturists operated largely in ignorance of each other and with considerable distrust, and this may have been due to the fact that education and training was entirely separate.

A working group of the International Federation of Dental Educators and Associations recommended in 2008 that "all members of the oral health team, to the extent possible, should be educated/trained together, in order that they may understand the roles they play as members of the team". ${ }^{6}$

The same group reported that the length of training of denturists varied throughout the world, from 18 months to three years, and part-time to full-time. ${ }^{6}$ There appears to be no common internationally accepted core curriculum.

\section{Economic issues}

In most countries there has been a perceived benefit that competition for the provision of dentures would bring down the costs and indeed Denturist Associations have used this as a major motivating factor, such as in Australia and some states in the US.

In other countries, the Denturist Associations have claimed that they can provide a better or more satisfactory service. ${ }^{1}$ This was the argument in the UK and Ireland, and has also been put forward in South Africa.

However, not only is there no objective clinical evidence of a superior service, but there is no evidence that the cost of denture provision is substantially different between denturists and dentists, especially in countries with a fairly robust national public health service with a regulated fee structure (which may be the case here in South Africa with the proposed National Health Insurance).

In New Zealand, álthough most denturists provide both metal and acrylic-based RPDs, the fees charged for the acrylic based RPDs were similar to those charged by dentists. ${ }^{4}$

In the USA, denturist services did not seem to be improving accessibility to low-income patients; it was felt that this was because denturists and dentists were serving patient groups from similar socio-economic backgrounds. ${ }^{3}$ In Finland, the availability of denture services in remote areas had not improved because both denturists and dentists were concentrated in the larger cities. ${ }^{3}$

In emerging economies such as South Africa, where almost all dental and laboratory equipment and supplies are imported, the overhead costs for a dentist and a denturist are likely to be fairly similar. How this will translate into lower costs for the patient, is not known.

It has been recommended that for emerging economies, the denturist should form part of the oral health team. ${ }^{6,7}$ This is because public funding (which is supposed to improve access) is likely to only be feasible if the workforce takes on shared responsibilities; which means that each member of the oral health team should provide competent and cost-effective care appropriate to their level. That is the main economic argument for the inclusion of denturists in that team. ${ }^{6}$

\section{Quality of service}

The fear expressed by especially some dental associations, that denturists would be unable to cope with denture-induced conditions could be allayed by better cooperation between dentists and denturists, including cross referrals. Patients with resorbed ridges often complain of looseness and an inability to chew and many dentists refer such patients to specialists.

Similarly, denturists should be encouraged to refer. Complaints such as denture stomatitis and denture-induced hyperplasia respond favourably to improved oral hygiene and minor denture adjustment; ${ }^{1}$ so if dentists 
could provide a diagnostic service for denturists this could alleviate any fears and denturists might blend in better as part of the oral health team.

In a study of the clinical quality of removable dentures provided by dentists, denturists and laboratory technicians in Finland, it was found that dentures provided illegally, whether complete or partial, had significantly higher occurrences of 'unacceptable characteristics', such as poor stability when speaking and eating, and 'food often catches underneath'. However, there seemed to be few differences between prostheses provided by dentists and denturists. ${ }^{8}$

\section{Occupational health}

Only one study could be found on the occupational health hazards in denturists, but it did not separate the hazards into those arising from clinical work from those arising from work in the laboratory. Nevertheless, denturists and those advocating for denturism should take note of some of the findings.

Clinical work on patients means an exposure to the risk of infection, notably from such biological contaminants as Hepatitis $B$ and $C$. There is a known relationship between the occurrence of back pain and paraesthesia in the arms and fingers, and this has been related to the long working hours of denturists (average 12-13 hours)..$^{9}$ In a study of Polish denturists the most common (defined as occurring daily or at least once a week) health problems were: back pain (70\%); chronic fatigue syndrome (62\%); irritation, itching and rashes on the hands (51\%); restlessness and aggression (43\%); and watery and itchy eyes (42\%). ${ }^{9}$

\section{Professional relations}

In New Zealand there appears to be a good relationship between dentists and denturists, with a relatively high proportion referring to each other. ${ }^{4}$ It is not clear, however, just what clinical procedures are carried out for the provision of RPDs (such as modification of the teeth to receive rests and guide planes) as this has not been reported in the literature.

In Finland, it was found that dentists and denturists in small towns or rural areas cooperated more often than those in urban areas. ${ }^{10}$ An investigation into the attitudes of dentists towards auxiliaries found that in Belgium and Greece, there was little or no support for any auxiliaries compared with the other countries investigated (Finland, UK, Canada and New Zealand), where the use of dental hygienists was supported, but not therapists and denturists. ${ }^{11}$

\section{CONCLUSION}

There seems little doubt from reported experiences around the world, that denturists can provide a valuable service in the provision of removable prostheses.

However, there would seem to be several caveats for this to happen without any detriment to the patient (or indeed to either profession).

\section{These are:}

1. The relationship between dentists and denturists needs to be respectful, cooperative and mutually supportive. This requires the acceptance by the dental profession and its associations of the principle of denturism.

2. The training of denturists must include the recognition of oral mucosal pathology.

3. If licensed for removable partial dentures, the design of the denture and the modification of the teeth must be carried out by a dentist.

4. Denturists, through their training, must understand when to refer cases which may be beyond their ability to treat successfully.

5. The scope of practice must be clearly regulated and based on the clinical treatment needs of the country as assessed scientifically.

6. It is suggested that initially, the scope should be confined to the edentulous patient only, and that scientific monitoring and evaluation of the services provided be undertaken independently, with a comparative monitoring and evaluation of general dental practitioners providing similar services.

7. The education and training could take a variety of forms. For example, from a post-graduation (from dental technology) course to a dedicated course only covering the scope of practice of the denturist as defined.

8. The dental profession (and preferably prosthodontists) must undertake the clinical aspects of the education and training of any category of denturist.

\section{References}

1. Mac Entee MI. Denturists and oral health in the aged. J Prosthet Dent. 1994; 71: 192-6.

2. Tsitã KMP, Owen CP. Analysis of the need for, and scope of träining in, maxillo-facial prosthodontics in the South African dental technology programme. SADJ. 2017; 72: 1-21.

3. Tuominen R. Removable dentures provided by dentists, denturists and laboratory technicians. J Oral Rehab. 2003; 30: 55-9.

4. Egan JG, Payne AGT, Thomson WM. Removable prosthodontic services, including implant supported by overdentures, provided by dentists and denturists. Journal of Oral Rehabilitation 2008; 35: 252-8.

5. Allen K, Farah CS. Dental prosthetist experience with oral mucosal screening and referral. Quintessence Int. 2014; 45: 891-7.

6. Nash D, Ruotoistenmäki J, Argentieri A, Barna S, Behbehani J, Berthold $\mathrm{P}$, et al. Profile of the oral healthcare team in countries with emerging economies. Eur J Dent Educ. 2008; 12 Suppl. 1: 111-9.

7. Nash DA. Envisioning an oral health care workforce for the future. Community Dent Oral Epidemiol 2012;40 (Suppl. 2): $141-7$.

8. Tuominen R. Clinical quality of removable dentures provided by dentists, denturists and laboratory technicians. J Oral Rehab. 2003; 30: 347-52.

9. Garus-Pakowska A, Leśniewska A, Gaszyńska E, Szatko F. Occupational exposure and health problems among Polish denturists: a population-based study in Łódź province. Int Dent J. 2016; 66: 237-46

10. Tuominen R. Cooperation and competition between dentists and denturists in Finland. Acta Odont Scand. 2002; 60: 98-102

11. Kravitz AS, Treasure ET. Utilisation of dental auxiliaries attitudinal review from six developed countries. Int Dent J. 2007; 57: 267-73 